\title{
Aesthetic, functional and physical features of glulam in building architecture
}

\author{
Mikhail Zhuravlev ${ }^{1, *}$, and Tatyana Zhuravleva ${ }^{1}$ \\ ${ }^{1}$ Samara State Technical University, 244,Molodogvardeyskaya st., 443100, Samara, Russia
}

\begin{abstract}
The main purpose of this research is to prove the efficiency of glulam to meet various architectural needs. The three features of glulam such as: plasticity and aesthetic value, functional efficiency, supporting properties and resistance to extreme conditions, are compared with the same features of concrete and steel, the most widely used materials nowadays. The methods are based upon actual test results and practical experience in creating glulam constructions. The research shows that plasticity of glulam allows to create complex curved surfaces and its surface and texture clearly demonstrate the unique aesthetic features of the elements made of this material. Glulam can also be efficiently used to create various space morphotypes such as compact rooms, linear vertical and horizontal space, hall space, space with a complex spatial configuration. It is also proved that glulam strength expressed in Constructive Quality Ratio (CQR) surpasses steel and concrete in supporting ability and its durability also exceeds steel structures durability and is comparable to concrete.
\end{abstract}

\section{Introduction}

Ecological lifestyle which is becoming more and more popular nowadays has a great influence on the choice of constructing materials and for that reason architects turn to wood more often now. It is used as finishing material and as a supporting structure as well but still there is a doubt in its durability, strength and economic efficiency. This leads to denial of glulam use in spite of many of its advantages but due to technological development the attitude to glulam is changing.

The main subjects of study now are the strength of industrial and engineering structures made of glulam [1,2] and detailed comparison of bonding performance of adhesive glulams [3]. Much study is devoted to glulam conditions in wet environment because this kind of environment is usually very harmful or even fatal for timber structures [4].

However, the main objective of this research is a comprehensive glulam study taking into account many different but just architectural factors such as constructive values, aesthetic expressiveness and functionality.

\footnotetext{
*Corresponding author: mihail_zhuravlev@inbox.ru
} 


\section{Methods}

According to Vitruvius [5] there are three aspects in architecture: venustas (esthetics), utilitas (practical use, functionality), firmitas (strength). Let us base our glulam efficiency study on these three aspects.

\subsection{Methods of glulam plasticity and aesthetic expressiveness research}

Shaping is a very important property for an architectural material. It is necessary for creating variable shapes and forms of different kinds. Thus the more opportunities in creating shapes the material gives the more valuable it is for architectural needs. Very often it is needed to create flat surfaces, planes with rythmically protruded elements, curve shells, complex spatial configurations. Appropriate plasticity is required to produce all of these shapes and forms and so the more ways of creating different shapes and forms we have, the more valuable for an architect the material is. The material with good shaping and plasticity properties represents a multipurpose material which can be used for plenty of different architectural tasks. We will consider several actual methods of creating steel, concrete and glulam products in this study and compare them.

Besides the shape esthetic view of a product is also formed by its surface quality and texture [6]. We will study the properties of glulam surface in order to prove the efficiency of using this material from this point of view.

\subsection{Glulam functional abilities research methods}

Efficient functionality of a structure is provided by a variety of forms of its functional elements. In order to estimate the functional efficiency of glulam we will consider such space morphotypes as cellular space, linear vertical and horizontal space, hall space, space with a complex spatial configuration, analyze the possibility of using these materials to create such morphotypes and compare the results with actual glulam and timber structures.

\subsection{Glulam physical and mechanical properties research methods}

Strength of a construction in architecture is defined mostly by its framework. Three features in turn define the strength of a constructive material: mechanical properties of a material specified by its inner structure, durability or the ability of a material to preserve its characteristics in time and the ability of a material to resist extreme effects such as earthquakes or fire.

We will refer to actual test results of glulam structures in this study. Strength and durability advantages of glulam over sawn materials are obvious so to get objective results we will compare glulam with steel and concrete, materials which are mostly used in constructing nowadays. 


\section{Results}

\subsection{Plasticity and aesthetic expressiveness research results}

The way of producing a structure and getting the final product influence directly the process of creating a building.

The simplest way of producing an item is linear molding. Most steel items are produced by this particular rolling method. In case of glulam it is a longitudinal cut. But for complex configurations this method is not suitable.

Steel gives us an opportunity to make items of various complex curved forms and shapes by means of casting. However, this method is hardly ever used because modern Steel Plants are aimed to produce unified items and it is too laborious and expensive to produce specific steel elements of variable sections. Glulam structures of complex shapes also require special processing conditions which can be provided only in factories with special equipment. The advantage of concrete in this case is that it gives an ability not only to make elements of variable sections but to cast them directly on site.

Steel and glulam allow to mill very detailed objects and minimize geometric errors. This method is used for example to make grooves in joints or complex profiles. So milling allows to make items completely ready to be installed on site. Inner structure of glulam makes it rather easy to mill complex structure elements while steel milling is a laborious and hard process which requires high precision and high quality equipment which in turn makes producing of such steel elements not expedient.

Steel and glulam elements can also be made by means of bending. Bending of a finished steel structure is mostly a hard and laborious process which leads to rise of time and labour resources and as a result increases expenses. Glulam bending on the contrary is appropriate because its anisotropic, fibrous structure allows to make complex curve elements and curved surfaces with much less effort at the stage of producing a structure. This method allows to distribute the material over the structure and thus reduce its dimensions and weight which in turn leads to saving materials (see Fig. 1).

Color and texture are very important features of a constructive element surface. Nowadays there are plenty of synthetic materials which can imitate all kinds of surfaces. But still the most valuable element is the one that does not need any further artificial decoration. Wood is a natural material with anisotropic inner structure and with its own texture. This unique texture formed by natural wood fibers provides glulam items with a high aesthetic value which is very important for achieving aesthetic expressiveness in architecture. (See Fig. 2). 


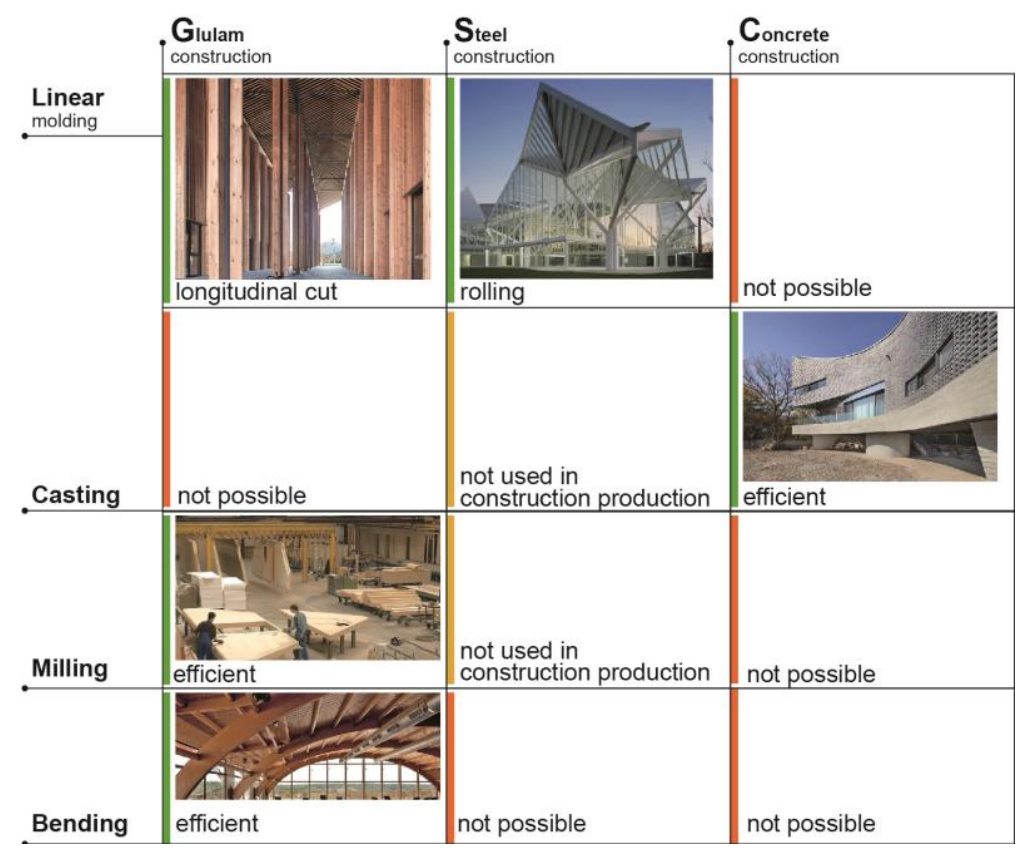

Fig. 1 Comparison of building materials by the way of forming a product, original work.

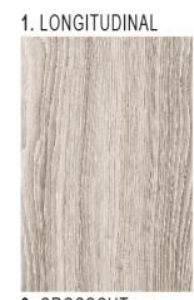

2. CROSSCUT

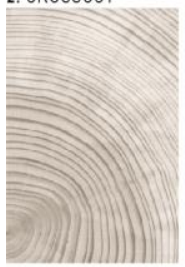

3. TANGENTIAL

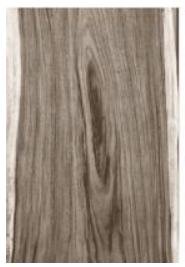

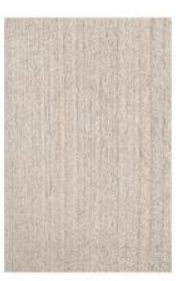
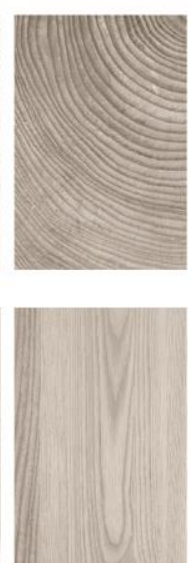
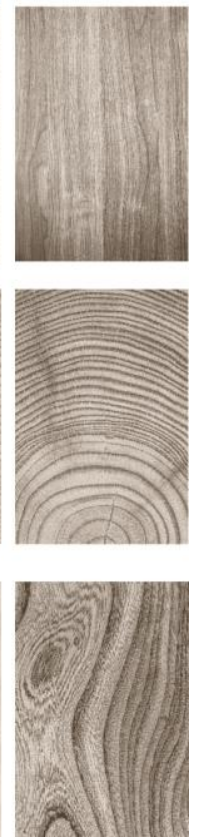

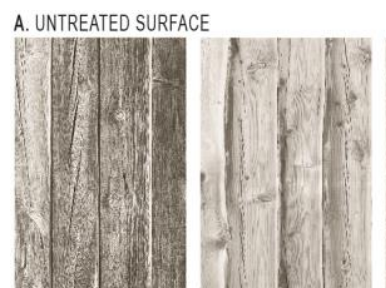

B. WHITTLED SURFACE

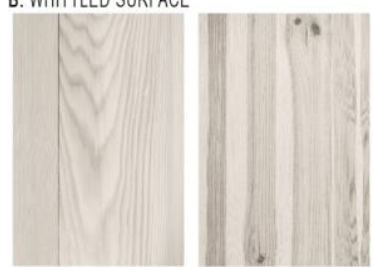

C. BRUSHED SURFACE
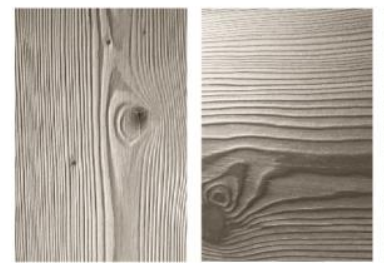
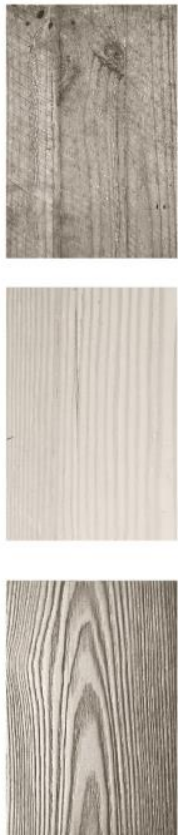

Fig. 2 Wood texture depending on cutting direction; original work. Wood surface quality depending on processing method; original work. 


\subsection{Glulam functional abilities research results}

We will determine the functional and planning efficiency of glulam structures by comparing traditional sawn material structures and glulam ones.

The main building schemes using traditional timber are frame system and log building. Structures made of untreated wood should be thick enough in section because environment damages or even destroys thin wooden elements rather quickly. Log building use logs of large section and is able to preserve the integrity of an untreated log as much as possible. However, there are angle restrictions on interlocking the logs: only right angle connection (4-, 5- and 6-walled constructions) and obtuse angle connection (6- and 8-wall construction) can be used. This circumstance strongly influences the space planning configuration of a building layout and leads to substantial span limits. layout and leads to substantial span limits.

The development of glulam technology has widened greatly the variety of opportunities of solving different space planning building problems [7]. For example, it became possible to produce columns and girders with large sections and due to that the value of overlapped span well increased (See Fig.4).

\subsection{Glulam physical and mechanical properties research results}

Three features define the strength of a constructive material. Let us study glulam efficiency referring to these three features.

\subsubsection{Mechanical characteristics of material specified by its inner structure}

The specialty of glulam inner structure comes from its natural origin. Fiber structure with pores and capillaries causes low density value $(335-400 \mathrm{~kg} / \mathrm{m} 3)$ while for example concrete has about $2500 \mathrm{~kg} / \mathrm{m} 3$ and steel has even more - 7800-7850 kg/m3. But in spite of such a difference glulam has comparable strength characteristics [8]. Different kinds of materials can be compared to each other by means of Constructive Quality Ratio (CQR), a special coefficient which represents the ratio of mechanical properties of the material to its density. This ratio gives us a clue to the efficiency of a material. For example, CQR of glulam is 2.2 while CQR of steel and concrete are 0.55 and 0.06 respectively. Weight is a very important characteristic of a supporting structure of a building especially in long span constructions and this ratio shows that glulam structures will have the smallest weight of all structures with other equal strength characteristics.

\subsubsection{Material durability}

Durability of a material is one of the most important features of a structure. Traditional timber structures are not very durable because first of all these structures are strongly affected by different environmental factors such as moisture or insects and besides timber is a rather flammable material. Low durability of sawn material also comes from its fast natural aging and strong fatigue stress [9]. But development of glulam technologies managed to minimize negative influences of these factors which in turn gave an opportunity not only to increase the strength of a material but also to enhance the lifetime of glulam 
buildings (up to 100 years). Practical experience of constructing glulam structures also showed its high durability efficiency in chemically aggressive environment.

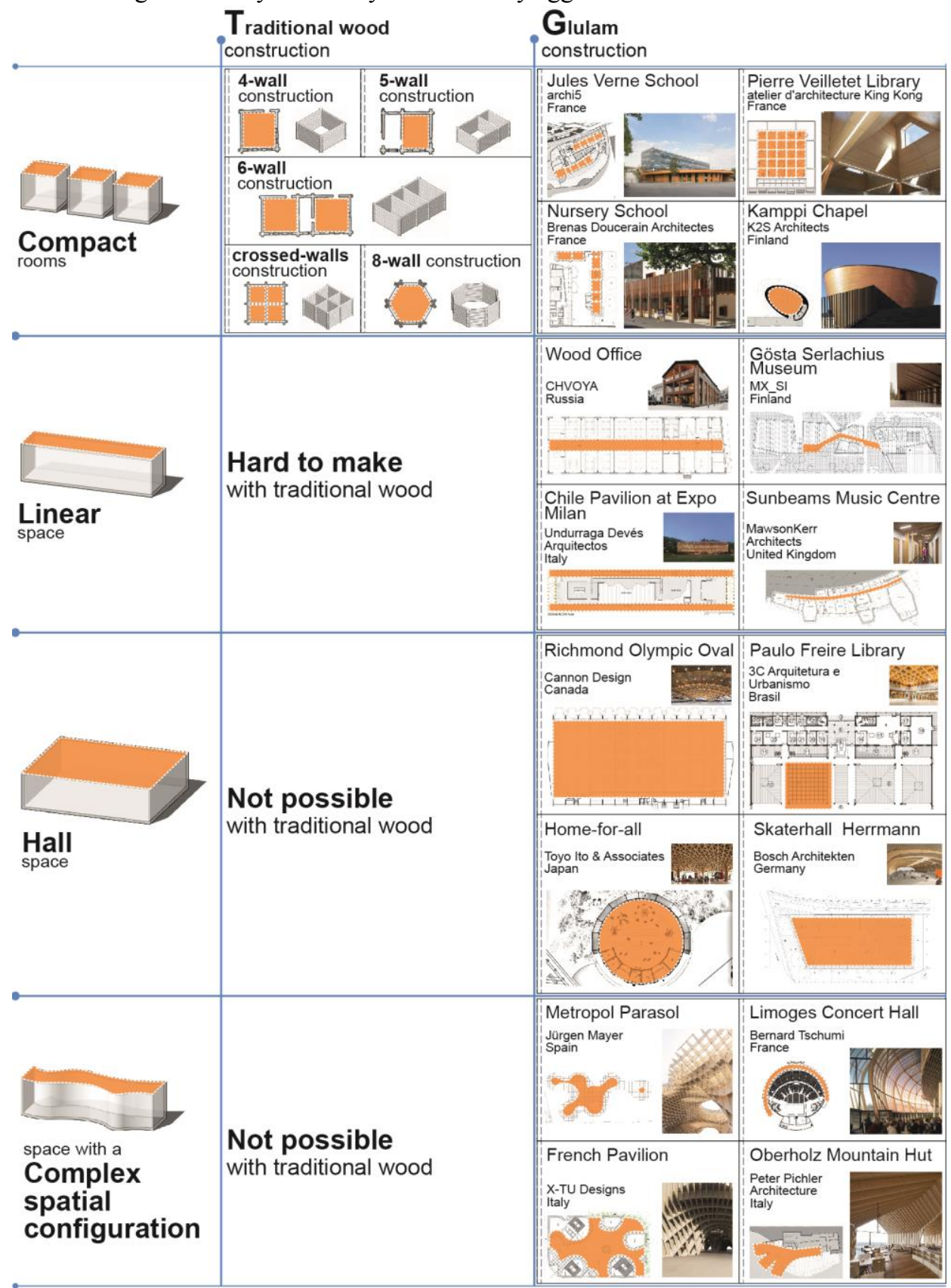

Fig.4. Glulam and timber structures functional abilities; original work.

Steel structures have a lifetime period of about 50 years but untreated steel items are not usually used in architecture. Corrosion processes which cause severe damage to steel constructions force to use serious protection methods and to create special maintenance conditions. 
Concrete structures have the longest lifetime period of up to 150 years. But for example chemically aggressive environment ruins concrete structures without special expensive additives rather quickly and they also require special maintenance conditions.

\subsubsection{Extreme effects resistance material ability}

The main purpose of any building is to protect from external environment and to provide safe life activity within its boundaries. Fire is one of the main dangers for a construction. It is believed that wooden structures are not durable and not safe mostly because wood is a flammable material. Steel and concrete are not flammable and that's why these materials are considered to be more secure. The analysis of glulam, steel and concrete burning process will help us to understand the differences between these materials.

Unprocessed glulam surface requires $4 \mathrm{~min}$ (6-7 $\mathrm{min}$ for a treated surface) to reach the ignition temperature and catch fire. After ignition, the rate of decrease in the cross section of the structural element is $0.6-0.7 \mathrm{~mm} / \mathrm{s}$ [10]. So the time necessary for a large glulam item to fully lose its supporting ability is quite enough for evacuation [11,12]. According to actual tests fire resistance of glulam is up to R150.

Steel is a very good heat conductor. That is why warming up of a constructive element occurs very quickly. When the critical temperature is reached the element abruptly loses its supporting ability. This kind of damage is very dangerous because it is almost unpredictable. That is why it is necessary to use special coating and different other methods of protection which much increase the cost of a construction. Fire resistance of untreated steel structure is about R10-15.

Concrete burning behaviour strongly depends on the location of its reinforcement. In bended elements reinforcement is located quite close to the item surface and that is why such elements lose their strength characteristics rather quickly. The fire resistance in this case is R90, because strength characteristics limit depends directly on the reinforcement. Fire resistance for compressed concrete structures is around R90-150.

Wind and seismic stresses on supporting structures also have a great influence on security and durability of the buildings. Due to inner structure glulam elements have small weight and it helps to carry great seismic stresses. CTBUH supports ecobuilding and suggests that glulam will be widely used to make skyscrapers [13-15] not only in stable but also in seismically dangerous regions.

\section{Discussion}

Glulam is easy to process due to its laminated structure and interchange of soft and hard fibers. There are several ways of making glulam elements: linear forming (cutting planks and beams), milling and bending. The only way that can not be applied to producing glulam elements is casting. Plasticity of glulam allows to create complex curved surfaces which is a highly demanded feature in architecture nowadays.

The study of glulam surface and texture clearly demonstrate the unique aesthetic features of the elements made of this material. Thus it becomes possible to refuse to use artificial materials many of which have been designed especially to reproduce the wood texture.

The study of glulam functionality in architecture based on the use of this material in different space morphotypes such as compact rooms, linear vertical and horizontal space, 
hall space, space with a complex spatial configuration showed us the functional efficiency of using glulam structures.

The results of strength study expressed in CQR confirms the superiority of glulam over steel and concrete in supporting ability.

Durability of glulam structures is up to 100 years which is comparable to concrete and exceeds steel structures durability.

The fire resistance rate of large section elements treated with special fireproof compounds but without constructive protection is up to $150 \mathrm{R}$ which confirms the high glulam resistance level to extreme environment. Creating bridges and high buildings in seismically dangerous regions using glulam structures prove their efficiency under extreme dynamic stresses.

\section{Conclusion}

Three glulam features have been studied in this research. Glulam is a pliable and esthetically expressive material and that is the first feature. Glulam structures can be applied to different space morphotypes and that makes the second feature. The third feature is the ability of glulam structures to effectively withstand and resist extreme environmental conditions. The results of these studies have showed the efficiency of glulam regarding to these aspects and allow to suggest that glulam structures will be variably and effectively used in the architecture of future.

\section{References}

1. M. Tazarv, Z.Carnahan, N. Wehbe, Engineering Structures 188, 11-23, (2019). https://doi.org/10.1016/j.engstruct.2019.03.012

2. B.Anshari, Z.W. Guan, Q.Y. Wang, Composite Structures 273, 160-170, (2017). https://doi.org/10.1016/j.compstruct.2017.01.028

3. J.Liu, K. Yue, L. Xu, J. Wu, Z. Chen, L. Wang, W. Liu, W. Lu, International Journal of Adhesion and Adhesives, 102500, (2019). https://doi.org/10.1016/j.ijadhadh.2019.102500

4. A.A. Chiniforush, A. Akbarnezhad, H. Valipour, S. Malekmohammadi, Construction and Building Materials 207, 70-83, https://doi.org/10.1016/j.conbuildmat.2019.02.114

5. M.P. Vitruvius, Ten books about architecture $1^{\text {st }}$ edn. Academy of architecture Publisher, (Moscow, 1936).

6. R. Phongkrathung, S. Vajrodaya, P.Kermanee, Agriculture and Natural Resources 50, 14-19, (2016). https://doi.org/10.1016/j.anres.2015.09.001

7. A. Kaiser, M. Larsson, U.A. Girhammar, Frontiers of Architectural Research 8, 1-16, (2019). https://doi.org/10.1016/j.foar.2018.12.001

8. P.H. Fleming, M.H. Ramage, Construction and Building Materials 230, 116952, (2020). https://doi.org/10.1016/j.conbuildmat.2019.116952

9. P. C. Raposo, J.A.F.O. Correia, D. Sousa, M. E. Salavessa, C. Reis, C. Oliveira, $\begin{array}{lllll}\text { Procedia Structural Integrity 5, 1097-1101, } & \text { (2017). }\end{array}$ https://doi.org/10.1016/j.prostr.2017.07.087

10. T.-H. Yang, S.-Y. Wang, M.-J. Tsai, Ch.-Yu. Lin, Building and Enviroment 44, 231236, (2009). https://doi.org/10.1016/j.buildenv.2008.02.010 
11. R. Darmon, O.Lalu, Procedia Manufacturing 32, 121-128, (2019). https://doi.org/10.1016/j.promfg.2019.02.192

12. F. Wiesner, L.A. Bisby, A.I. Bartlett, J.P. Hidalgo, S. Santamaria, S.Deeny, R.M. Hadden, Engineering Structures 179, 284-295, (2019). https://doi.org/10.1016/j.engstruct.2018.10.084

13. J.L. Skullestad, R.A. Bohne, J. Lohne, Energy Procedia 96, 112-113, (2016). https://doi.org/10.1016/j.egypro.2016.09.112

14. M.H. Ramage, H. Burridge, M. Busse-Wicher, G. Fereday, T. Reynolds, D.U. Shah, G. Wu, L. Yu, P. Fleming, D. Densley-Tingley, J. Allwood, P. Dupree, P.F. Linden, O. Sherman, Renewable and Sustainable Energy Reviews 68, 333-359, (2017). https://doi.org/10.1016/j.rser.2016.09.107

15. A.P. Kern, L.V. Amor, S.C. Angulo, A. Montelongo, Waste Management 78, 446-455, (2018). https://doi.org/10.1016/j.wasman.2018.05.057 